\title{
Los caminos del patrimonio. Rutas turísticas e itinerarios culturales
}

\author{
Javier Hernández Ramírez \\ Universidade de Sevilla (España)
}

\begin{abstract}
Resumen: En este trabajo se analizan las causas que explican la proliferación de rutas turísticas e itinerarios culturales como un fenómeno global y las consecuencias que pueden tener en los territorios donde se implantan. Se establece una tipología de rutas y se estudia el controvertido concepto de Itinerario Cultural conforme a las propuestas del Consejo de Europa e ICOMOS. Posteriormente se examinan distintos proyectos de rutas y caminos históricos en la sierra de Ayabaca (Piura, Perú) y se abordan los potenciales impactos que la creación de estos productos turísticos pueden suponer para el desarrollo de las poblaciones donde se aplican. En el artículo se plantea que los proyectos de rutas diseñados en el área de estudio carecen de una visión holística del patrimonio que promueva su puesta en valor como conjunto, por lo que fragmentan el territorio al dinamizar unas zonas en detrimento de otras.
\end{abstract}

Palabras clave: Rutas turísticas, Itinerarios Culturales, ICOMOS, Consejo de Europa, Marketing territorial.

Title: The roads of the heritage. Tourist routes and cultural itineraries

Abstract: In this work, the reasons for the proliferation of tourist routes and cultural itineraries as a global phenomenon together with the consequences that these can trigger in the territories where they are introduced are analysed. A typology of routes is established and the controversial concept of Cultural Itinerary based on the proposals of the European Council and ICOMOS is studied. Various projects involving routes and historical paths in the Ayabaca mountain range (Piura, Peru) are then examined, as are the potential impacts that the creation of these tourist products can suppose for the development of the populations where they are applied. It is considered in this paper that these projects lack a holistic vision of heritage that would promote its value as a whole, thereby preventing the potential fragmentation of the territory as regards encouraging some zones to the detriment of others.

Keywords: Tourist routes; Cultural Itineraries; ICOMOS; European Council; Territorial Marketing.

i Profesor titular del Departamento de Antropología Social de la Universidade de Vigo. E-mail: jhernan@us.es 


\section{Marketing territorial y proliferación de rutas culturales}

En los últimos años asistimos a la multiplicación de rutas e itinerarios turísticos por todos los rincones del planeta (Briedenhann y Wikens, 2003; Denstadli, y Jacobsen, 2010; López-Guzmán y Sánchez, 2008; Rengifo, 2006). En su diversidad, estos productos coinciden en poner en el mercado un territorio que, por sus características y valores presuntamente singulares, pretenden atraer la visita de consumidores potenciales. A diferencia de etapas pasadas en las que lo habitual era que la oferta la constituyera un destino específico -ya fuera éste un paraje, localidad, monumento del pasado o espacio para el placer-, en la actualidad la oferta se diversifica al comercializarse un territorio completo que, bajo un denominador común, trata de conducir a los visitantes siguiendo un recorrido definido y delimitado. El fenómeno supone la extensión del modelo de guía turística del ámbito urbano a espacios más amplios, contribuyendo a la expansión de la actividad a territorios anteriormente poco transitados o a la ampliación de un mercado preexistente. Al igual que las guías que orientan la visita en las ciudades, las rutas pretenden conducir las actividades resaltando qué es lo que merece la pena conocerse del nuevo territorio turístico. Para ello son construidas narrativas que reelaboran e incluso generan nuevas imágenes y significados de los lugares, subrayando determinados aspectos considerados sugestivos aun cuando puedan ser del todo ajenos a las poblaciones que habitan dichos entornos.

El fenómeno se inserta en dos dinámicas complementarias. De un lado, la creciente reflexividad social sobre la crisis del medio ambiente y de autenticidad de las culturas, que en el terreno de la práctica turística se manifiesta en un deseo cada vez más generalizado por conocer espacios naturales, sociedades singulares y bienes patrimoniales; y de otro, la expansión social del patrimonio que implica el surgimiento de nuevas categorías patrimoniales como las de paisaje e itinerario cultural. Este es el contexto social, cultural e intelectual que subyace a la proliferación de rutas turísticas de todo tipo a escala global. En su diversidad de contenidos y dimensiones, todas tienen en común la proyección de un territorio para el consumo turístico a través de una vía, ya sea ésta terrestre, fluvial o marítima.

El aumento de rutas se produce en un momento histórico de consolidación de una compleja industria transnacional y de un mercado global muy competitivo en el que participan diversos actores públicos y privados. A través de un marketing territorial que basa la competitividad en la actividad turística, estos actores persi- guen maximizar la posición de sus destinos en el contexto internacional ofreciendo atractivos singulares en un mercado global (Filardo, 2006). En esta competencia territorial, las rutas turísticas constituyen un producto idóneo y recurrentemente utilizado para la promoción de espacios concretos.

En el diseño y ejecución de las rutas intervienen sistemas expertos (Denstadli, y Jacobsen, 2010; Giddens, 1993) formados por organismos y profesionales especialistas, generalmente externos a los destinos turísticos (consultoras, operadores turísticos, universidades, empresas públicas, organizaciones no gubernamentales, etc.) que, con la financiación de las administraciones locales, regionales, nacionales e incluso internacionales y el apoyo de muy diversos grupos de interés, ordenan, planifican y establecen las líneas estratégicas de desarrollo del lugar. Recurriendo a metodologías diseñadas y normalizadas por instituciones internacionales y nacionales (OMT, UE, OEA, organismos públicos estatales, etc.), estos agentes producen un espacio turístico que reinterpreta e incluso modifica la realidad cultural previa para proyectar competitivamente al lugar en el escenario planetario (Lagunas, 2006). De este modo, las rutas son creadas aplicando procedimientos cada vez más estandarizados de clasificación y registro de los recursos patrimoniales y paisajísticos, que permiten seleccionar y objetivar aquellos bienes culturales y ecológicos que son susceptibles de transformarse en productos turísticos, organizando y jerarquizando la oferta según su interés turístico. En esta operación instrumentalizan el apego a la memoria, a la tradición y a la naturaleza característico de nuestra época, ajustando la imagen de los territorios a estos valores globales muy demandados por los turistas, los cuales no se corresponden necesariamente con la dinámica socio-cultural interna del territorio que se pretende promocionar (Nogués, 2006). Asimismo, con el objetivo de alcanzar una mayor proyección internacional, con frecuencia hacen suyos los avances conceptuales que en materia de patrimonio propagan instituciones de alto prestigio internacional como UNESCO y el Consejo de Europa, adaptando las rutas a los modelos sugeridos por estas instituciones supranacionales y por otros organismos nacionales y regionales.

La creación por doquier de rutas turísticas evidencia que, en la actualidad, las estrategias locales de desarrollo se realizan de acuerdo con las tendencias globales del turismo internacional (Aguilar, et al, 2003). En estas iniciativas que se expanden y reproducen por todo el planeta, lo local se configura de acuerdo con los patrones globales que construyen y definen las cualidades que deben contener los territorios susceptibles de ser idóneos escenarios para el consumo turístico. Así, 
para ofertar globalmente los espacios locales, estos son transformados en productos que reúnen los atributos de excepcionalidad, pureza, autenticidad, historia o tradición (a veces todos juntos) que son del gusto del consumidor global. Todo ello revela, tal como plantea Urry, que el "turismo" y lo "global" no deberían interpretarse como fenómenos independientes que establecen vínculos externos entre sí, sino que ambos fenómenos están interconectados dentro del mismo conjunto de procesos complejos (2008).

\section{Rutas, caminos históricos e itinerarios culturales}

Estos recorridos turísticos, que toman distintas denominaciones tales como corredores, rutas, circuitos, caminos o itinerarios, tratan de diferenciarse de sus competidores resaltando determinados recursos que están presentes en el territorio o que son imaginados y creados artificialmente. En el primer caso se invita al visitante a recorrer un periplo en el que predomina una determinada categoría patrimonial, ya sean manifestaciones culturales, testimonios del pasado arqueológico o histórico, patrimonio artístico, industrial o espacios naturales. Ejemplos de estos productos serían las rutas gastronómicas y enológicas, que basan su oferta en el aprovechamiento turístico de los recursos agropecuarios de un territorio (López-Guzmán y Sánchez, 2008); las rutas mineras e industriales, que trazan su recorrido por antiguas explotaciones (García de Miguel, 2002; Fernández y Guzmán 2005); las que orientan el viaje al descubrimiento de un estilo arquitectónico abundante y característico de una zona (Campesino, 2006; Proyecto Andalucía Barroca, 2007) o a la contemplación y disfrute de paisajes poblados por especies autóctonas (Aguña, 2002; López Roig, 2008). Una modalidad de estos trazados temáticos específicos, que serán analizados más adelante, son aquellas vías turísticas reconocidas (o aspirantes a serlo) por administraciones públicas internacionales como itinerarios culturales por sus destacados testimonios históricos, artísticos y/o etnológicos.

Pero en este afán diferenciador se recurre también al diseño de un segundo tipo de rutas, las cuales recrean el territorio a través de nuevos atractivos que poco o nada tienen que ver con la realidad histórica y cultural de los destinos, pero que se incorporan como valores añadidos a los mismos. Ejemplos interesantes de esta tendencia serían las rutas literarias y cinematográficas que ponen en valor las localizaciones de filmes célebres, series televisivas y emplazamientos de novelas. Aquí el lugar es reinventado y se persigue estimular a los turistas a revivir con su particular mirada vicaria lo que antes leyeron en novelas o contemplaron en la pequeña o gran pantalla (Herbert, 2001; Hernández, 2005). Otras rutas similares son aquellas que exaltan determinadas figuras históricas o personajes de ficción con el diseño de los itinerarios por los que transitaron o vivieron. El Camino del Cid, que discurre por varias provincias españolas siguiendo las huellas del caballero medieval descritas en el Cantar del Mío Cid; la Ruta del Quijote en Castilla la Mancha (Campos, 2006) o las de los Bandoleros en Andalucía (Zamora y Merinero, 2003) ilustran un modelo cada día más frecuente. Otros trazados obedecen a un diseño basado en leyendas y mitos -casi siempre adaptados muy libremente y con una buena dosis de elucubración histórica- que trata de inducir al turista a viajar por sitios particulares de los que se dice que poseen un encantamiento que trasciende. De estos recorridos se suele destacar la presencia de restos prehistóricos (dólmenes, necrópolis, petroglifos...) y medievales (fortalezas, ermitas, iglesias...) junto con accidentes geológicos llamativos a los que se atribuyen propiedades curativas y/o mágicas (aguas, barros, plantas medicinales...), así como la celebración de rituales perdidos o vigentes pero presentados como atávicos. Los espacios que recorren estas rutas son mostrados como insólitos y cargados de leyendas que refieren a acontecimientos, personajes históricos e incluso fantásticos (templarios, duendes, magos, hadas, gigantes, fantasmas, brujas...) combinados a veces con interpretaciones esotéricas sobre las propiedades del lugar (Inglis y Holmes, 2003; Otamendi, 2008). Ejemplos interesantes de esta modalidad de rutas son las propuestas de turismo por la Guadalajara mágica (España) (www.alcarria.com) o las rutas por las lagunas de los páramos (Huaringas) de Huancabamba (Piura, Perú) que recurren al chamanismo como atractivo turístico (http://www.perutravels.net).

Un tercer tipo de rutas serían aquellas mixtas que se diferencian de las anteriores, de carácter monográfico, por carecer de un eje temático definido y por responder a una oferta territorial genérica. Son rutas eclécticas en las que, siguiendo determinadas propuestas del marketing, el producto turístico se forma a partir de la suma de varios componentes, los cuales son prescindibles y sustituibles por otros. De acuerdo con esta lógica mercantil, las rutas son diseñadas artificialmente mediante la selección de una serie de hitos patrimoniales y recreativos que son asociados arbitrariamente bajo una etiqueta o lema común en la que se mezclan propuestas de visita y actividades heterogéneas. El resultado es la creación de una geografía turística imaginada y diseñada donde se establecen nuevos vínculos territoriales a partir de la promoción de un mosaico de recursos de lo más variopinto. Una variedad de esta última modalidad de rutas lo constituyen las promovidas por operadores 
turísticos bajo la denominación común de circuitos. La mayor parte de estas iniciativas son gestionadas por el sector privado sin la intervención directa de los poderes públicos ni los actores locales, por lo que su rentabilidad es externalizada y periférica. Generalmente toman como escenario espacios reconocidos institucionalmente como patrimoniales, sobre todo aquellos inscritos en catálogos públicos y especialmente los declarados Patrimonio de la Humanidad, lo cual es ampliamente subrayado en la publicidad. La oferta de circuitos es similar a la del turismo de masas, pues suele combinar en "un todo incluido" el alojamiento, la manutención, la movilidad y la visita a los atractivos turísticos de la zona en itinerarios programados en un periodo de tiempo específico (Rengifo, 2006). Un ejemplo paradigmático de este último tipo es la Ruta de la Plata, una antigua vía que discurre por la zona más occidental de España que, en sus distintos tramos y con el apoyo público de una red de ciudades asociadas, es explotada por agencias de viajes y mayoristas que ofertan paquetes turísticos orientados al consumo simultáneo de atractivos turísticos tan diversos como la gastronomía, el medio ambiente, los conjuntos históricos, las costumbres y tradiciones populares, junto con actividades lúdicas y deportivas (http://www.rutadelaplata.com)

Los caminos históricos constituyen una última categoría de rutas. Estos trayectos son promovidos generalmente por organismos públicos con el objetivo del reconocimiento institucional de los mismos como itinerarios culturales a través de su inscripción en catálogos oficiales de bienes culturales. Este fenómeno se produce en un marco de competencia territorial global donde los gestores de las rutas se afanan por dar a conocer su producto en el mercado turístico internacional. La consecución de esta meta supone un importante respaldo político y un notable impulso promocional que se traduce casi automáticamente en el incremento de los flujos turísticos (Rengifo, 2006). Esto es más evidente cuando el producto se integra en inventarios internacionales como el del Consejo de Europa y más claramente en la Lista del Patrimonio Mundial sobre todo tras el reconocimiento por parte de la UNESCO, en 2005, de las Rutas Patrimoniales (o itinerarios Culturales) como categoría específica. Este objetivo se convierte en algunos casos en el que motiva la propia creación del producto, como es el caso de la Ruta Don Quijote que fue diseñada ex profeso en 2004 para formar parte de la Red de Itinerarios Culturales Europeos (Campos, 2006) en la que se integra desde 2007. Este tipo de rutas patrimoniales reconocidas o aspirantes a la categoría de Itinerario Cultural las denominaremos caminos históricos por su mayor énfasis en los testimonios del pasado que jalonan

\section{el recorrido.}

En 1987 el Consejo de Europa inscribió el Camino de Santiago como el primer Itinerario Cultural Europeo y en 1993 esta misma ruta fue registrada por la UNESCO como Patrimonio de la Humanidad. Desde entonces el número de vías reconocidas internacionalmente no ha parado de crecer, lo que ha motivado a muchas administraciones promotoras de rutas turísticas a postularse como candidatas para la anotación de sus propuestas en los catálogos de estas instituciones supranacionales. Ante tal incremento de candidaturas, estos organismos han establecido criterios definitorios y restrictivos para inscribir itinerarios en sus catálogos. Para cumplir tales requerimientos, los candidatos se esfuerzan por argumentar el carácter cultural de sus propuestas, tratando de ajustar su oferta a los criterios de los organismos internacionales. Salvando las distancias, el fenómeno es similar al que se produce con las candidaturas de ciudades para la celebración de Olimpiadas; en ambos casos lo que subyace en todo este proceso es el objetivo de posicionamiento estratégico en el mercado turístico global y la pugna por atraer a los territorios turistas, capitales e inversores.

El establecimiento de las directrices que deben definir a los itinerarios culturales en contraposición a las rutas turísticas ha abierto un interesante debate sobre esta nueva categoría patrimonial. El Consejo de Europa promueve la creación de vías que impulsen la conciencia e identidad europea, la cooperación internacional y fomenten el desarrollo económico, para lo que se creó en 1997 el Instituto Europeo de Itinerarios Culturales. Desde esta óptica el patrimonio cultural se interpreta como un instrumento para alcanzar estos fines y los itinerarios como un producto que los facilita. En palabras de la responsable de los Itinerarios Culturales Europeos, Françoise Tondre: "El concepto de patrimonio sobre el cual se fundan los Itinerarios Culturales difiere de aquel que sostiene la política de la UNESCO en materia de patrimonio mundial. Efectivamente, la UNESCO considera como patrimonio cultural aquello que tiene < un valor universal excepcional desde el punto de vista de la historia, del arte o de la ciencia $>-$ un patrimonio que apela a valores comunes de la humanidad. La prioridad del Consejo de Europa es el vínculo que une el patrimonio y la comunidad, así como el patrimonio como recurso para el desarrollo sostenible" (2007: 32). Esta visión contrasta con la que propone el Consejo Internacional de Monumentos y Sitios (ICOMOS) que, a través del Comité Científico Internacional de Itinerarios Culturales (CIIC), ha organizado distintos encuentros y conferencias internacionales para perfilar un concepto de itinerario cultural, el cual se ha sustanciado 
en la Carta de los Itinerarios Culturales de ICOMOS (2008). Este documento fija las normas que regulan la inclusión de los itinerarios en la Lista del Patrimonio Mundial a partir de requisitos que, con una pretensión de objetividad y rigor científico, distingue entre itinerarios culturales y propuestas diseñadas con criterios espurios al objetivo de puesta en valor del patrimonio cultural. Según el vicepresidente de ICOMOS-España. "No pueden confundirse los itinerarios culturales con las rutas turístico-culturales, porque los primeros responden a criterios históricos de autenticidad, de continuidad y de intercambios contrastados entre culturas, mientras que las segundas son invenciones turísticas de conveniencia, promovidas por agentes públicos o privados, que hilvanan redes de recursos patrimoniales más o menos homogéneos y vinculados entre sí para la oferta de un producto comercial prefabricado y virtual, en ocasiones tematizado y autoconstruido con nula base científica, como promueve el propio Consejo de Europa con el eslogan: <cree usted su propio itinerario cultural>" (Campesino, 2006: 1).

Como se ve, la definición de itinerario cultural es motivo de controversia entre estos organismos supranacionales. ICOMOS propone una noción que se apoye en hechos históricos reales haciendo referencia a vías que hayan favorecido la inter-fecundación de culturas en el espacio y el tiempo (Capel, 2005); mientras que el Consejo de Europa opta por una definición más abierta que incluya todo tipo de trazados que contribuyan al acercamiento y la cooperación entre pueblos (especialmente localizados en estados distintos), difundan la cultura, memoria e identidad europea y promuevan el desarrollo turístico (Consejo de Europa, 1998). ICOMOS critica esta definición por falta de rigor científico y no acepta que los itinerarios culturales respondan a propuestas artificiales en las que prevalezca "la imaginación y la voluntad de establecer conjuntos asociativos de bienes culturales que posean rasgos comunes" que vinculan, por meros motivos de oportunidad político-culturalmercantil, a tres o cuatro puntos geográficos próximos entre sí (ICOMOS, 2008: 1). Como alternativa propone fomentar el reconocimiento de itinerarios culturales que pongan en valor caminos en los que históricamente haya existido "una dinámica habitual de recorridos con un carácter funcional, es decir, conexiones históricas destacables y permanentes a través de un itinerario comúnmente practicado (Suárez-Inclán, 2004).

ICOMOS distingue dos tipos de itinerarios culturales: en primer lugar, las rutas históricas trazadas para dar curso a un propósito determinado, como por ejemplo, el Qhapaq Nan o Camino Inca y las calzadas del Imperio Romano; y en segundo, aquellas que son resul- tado de largos procesos evolutivos en los que intervienen distintos factores humanos que coinciden y se encauzan a un mismo fin, como por ejemplo el Camino Santiago, las rutas de caravanas comerciales africanas o la Ruta de la Seda (ICOMOS, 2008). Salvo en ejemplos muy particulares, la mayoría de los itinerarios culturales reconocidos corresponden a la primera categoría, porque son caminos históricos que fueron concebidos hace tiempo con un propósito determinado que ya se ha extinguido. Pero difícilmente pueden hallarse muchos ejemplos de recorridos de la segunda categoría, es decir, de itinerarios con conexiones históricas permanentes o de largo recorrido histórico, como es el caso de la Vía Jacobea. La causa probable es que este último tipo sólo contempla situaciones muy excepcionales -verdaderas anomalías históricas- en las que pueda hablarse de continuidad del camino en un sentido material y simbólico. Y es que el significado de itinerario así planteado suscita una cuestión de fondo: ¿Cómo es posible fijar en conceptos estáticos y recurrentes lo que es por esencia movilidad y cambio permanente? (Palti, 2001:11). ¿Cómo establecer una unidad entre pasado, presente y futuro a partir de una sustancialidad del devenir?, ¿es posible una historia en la que las mismas situaciones básicas se repitan recurrentemente en un territorio concreto?

La dificultad evidente para justificar itinerarios culturales como resultado de largos y continuos procesos evolutivos explica que la mayor parte de las vías que se postulan con posibilidades de éxito para ser reconocidos por ICOMOS hagan referencia al pasado y, consiguientemente, al patrimonio histórico. Esto se aprecia con claridad si atendemos a los principales itinerarios culturales identificados por los miembros del CIIC de ICOMOS en América Latina y España. Sin ánimo de ser exhaustivos destacan los siguientes: El Camino Real Continental, Itinerarios vinculados a la Minería Histórica, el Camino del Inca, la Ruta del tránsito en Nicaragua, las calzadas romanas o las rutas de la Trashumancia en España. En todos ellos el interés del itinerario descansa en el pasado y, por tanto, lo que se subraya como la manifestación más relevante es el legado histórico tangible, que constituye su eje temático. Y esto tiene sus consecuencias, ya que desde este enfoque, los bienes del patrimonio etnológico y ecológico son resaltados como atractivos asociados, dependientes y subordinados a los históricos. De este modo se produce una jerarquización del patrimonio, la cual entra en contradicción con una perspectiva holística del itinerario cultural entendido como categoría que identifica y ensalza cada bien cultural y amplía su significado como parte sustantiva de un conjunto (Suárez-Inclán, 2004).

Con independencia de la pertinencia de las definicio- 
nes de itinerario cultural que promueven los organismos citados, el carácter restrictivo de los criterios tiene como consecuencia más directa el freno de la avalancha de candidaturas a figurar en los catálogos oficiales. Por ello no es extraño que, en ocasiones, los intelectuales y técnicos al servicio de las propuestas que se postulan como itinerarios culturales procedan a la recreación histórica y a la producción de mitos de continuidad para ajustar forzadamente dichos territorios a tales definiciones y criterios. Estos académicos y profesionales certifican con su autoridad científica socialmente reconocida determinadas interpretaciones de la realidad, construyendo narrativas que reescriben la historia mediante una visión cargada de esencialismo, que remite a la continuidad del sentido histórico del camino, y generan nuevas imágenes y significados de los lugares ajenos a las poblaciones que los habitan. De este modo, la realidad histórica y antropológica se ajusta con calzador al concepto, produciendo mitos postmodernos que pueden ser posteriormente instrumentalizados por la ingeniería turística que produce rutas culturales.

En definitiva, la realidad empírica muestra la existencia de diversidad de tipos de rutas que se sintetizan en la Tabla 1.

A pesar de esta variedad de propuestas, de escalas territoriales y de actividades posibles, el procedimiento de transformación de un espacio en territorio turístico es siempre similar. Todas las rutas tratan de ajustarse a las demandas globales de autenticidad y singularidad de distintos sectores de turistas y a los segmentos de mercado que se imponen en el turismo cultural internacional. El discurso que subyace a esta gama de ofertas es que, a través del camino, el visitante podrá adentrarse en un mundo particular y vivir experiencias únicas; pero el objetivo implícito es la creación de productos turísticos que sitúen o consoliden a determinados ámbitos territoriales (comarcas, términos municipales, espacios transfronterizos, etc.) en el escenario turístico global. Este modelo supone una visión instrumental del territorio y su patrimonio concebidos como recursos que pueden transformarse mediante determinados procesos (creación de servicios, adecuación del entorno, generación de imagen, difusión...) en productos turísticos. Pero el éxito de estas propuestas puede generar consecuencias que superan las estrictamente económicas: de un lado, pueden desencadenar nuevas formas de cooperación entre administraciones y poblaciones vecinas (Briedenhann y Wikens, 2003); y, de otro, pueden implantar nuevas imágenes territoriales, culturales e históricas que sustituyan o convivan con las tradicionales. Tal como indica Nogués (2006) para el caso de la comarca de la Bonaigua (Alicante), suele ocurrir que, cuando estas operaciones son avaladas o lideradas por las administraciones, el escenario turístico y los atributos seleccionados son transformados en nuevos marcadores de la identidad territorial, lo cual no deja de ser una paradoja, pues éstos son diseñados según criterios globales de autenticidad, pureza o vida rural.

\section{Rutas turísticas y caminos históricos en los An- des septentrionales del Perú}

Una muestra de que el fenómeno de las rutas turísticas alcanza una dimensión planetaria es el caso de la sierra de Ayabaca (Piura, Perú): un territorio de frontera y periférico situado en una de las áreas más pobres y deprimidas del país andino que, sin embargo, contiene un riquísimo patrimonio etnológico, ecológico y arqueo-

\begin{tabular}{|c|l|}
\hline \multicolumn{1}{|c|}{ Rutas } & \multicolumn{1}{c|}{ Subtipos } \\
\hline \multirow{4}{*}{ Específicas Patrimoniales } & Rutas del Patrimonio Etnológico \\
\cline { 2 - 2 } & Rutas del Patrimonio Histórico y/o arqueológico \\
\cline { 2 - 2 } & Rutas del Patrimonio Natural \\
\cline { 2 - 2 } & Caminos Históricos e Itinerarios Culturales \\
\hline \multirow{2}{*}{ Específicas Imaginadas } & Literarias-cinematográficas-televisivas \\
\cline { 2 - 2 } & Personalidades históricas y personajes ficticios célebres \\
\cline { 2 - 2 } & Mágicas, esotéricas, míticas, legendarias \\
\hline Genéricas o mixtas & Mosaico de recursos (rutas y circuitos) \\
\hline
\end{tabular}

Tabla 1. Tipos y subtipos de rutas. Elaboración propia. 
lógico. Dadas las precarias condiciones materiales de existencia de la mayor parte de esta población andina y la paradoja de que estamos ante un entorno de gran diversidad y riqueza patrimonial, desde instancias políticas locales, regionales y nacionales se ha interpretado que el desarrollo turístico es una vía fundamental para la dinamización económica de la región y, dentro de esta estrategia, la creación de rutas el instrumento territorial más apropiado para alcanzar dicho objetivo.

En los últimos años se han sucedido distintos diagnósticos y propuestas de rutas diseñados por organizaciones no gubernamentales (internacionales y nacionales) y consultoras, financiados por organismos públicos, que han trabajado con variados objetivos y orientaciones teórico-prácticas. Entre los proyectos destacan cuatro trayectos: la Ruta Montero-Ayabaca-Aypate; el Corredor Turístico Loja-Ayabaca; el Proyecto Binacional de Turismo Rural en el Tramo Norte del Camino Inca (Loja-Aypate); y el Programa Integral Qhapaq Nan. Cada uno de estos proyectos responde, como veremos, a distintas concepciones patrimoniales y a tipologías de rutas indicados anteriormente: el primero se ajusta al modelo mixto o genérico; el segundo al de corredor del patrimonio natural; el tercero al específico de patrimonio arqueológico, y el último al de camino histórico. Sin embargo, hasta ahora ninguno de estos cuatro proyectos se ha materializado en un itinerario concreto debido a las dificultades que supone su puesta en funcionamiento en una zona extremadamente periférica, mal comunicada, con una enorme carencia de infraestructuras y equipamientos, y habitada por una población mayoritariamente campesina sin experiencia en el sector turístico y con escasos recursos económicos.

La Ruta Montero-Ayabaca-Aypate fue impulsada por el Gobierno de la Provincia Fronteriza de Ayabaca con el auxilio de la cooperación internacional española y dos organizaciones no gubernamentales que operan en la zona: Naturaleza y Cultura Internacional (NCI) e Instituto de Gestión de Cuencas Hidrográficas (IGCH). Estas instituciones suscribieron un convenio de cooperación y contrataron a una consultora externa con sede en Lima para la elaboración de un diagnóstico sobre las potencialidades de la ruta. El diseño del itinerario responde a una estrategia de desarrollo económico territorial a partir del turismo sin base científica, por lo que la selección del territorio se justifica simplemente por la pertenencia de las poblaciones por las que discurre el camino a la provincia de Ayabaca (Piura) y la frágil situación económica de sus habitantes. No son, por tanto, atributos específicos (paisajísticos, históricos, etnológicos o medioambientales) los que justifiquen la creación de la ruta, sino tan solo criterios administrativos defini- dos por el gobierno que realiza el encargo a la empresa consultora. Sobre esta propuesta territorial previa fue elaborado un diagnóstico, que sugiere la creación de una típica ruta genérica o mixta formada por toda una variedad de recursos ambientales y patrimoniales carente de un hilo conductor que proporcione un contenido temático integrador y coherente. El diagnóstico realizado sigue un modelo convencional de oferta y demanda que carece de una metodología basada en el trabajo de campo etnográfico, la investigación histórica y el análisis territorial para determinar los bienes patrimoniales y los recursos medioambientales y turísticos. Concluye con la habitual matriz DAFO como herramienta para subrayar las debilidades, amenazas, fortalezas y debilidades del destino. Sin embargo, dadas las limitaciones metodológicas y el superficial trabajo de investigación, este instrumento convencional no permite verificar con rigor la situación de partida y las potenciales ventajas competitivas de la ruta. El resultado es un informe que no se plantea probar la existencia de un territorio con características singulares que permitan construir una ruta temática, tan sólo se propone la construcción de un recorrido jalonado por bienes patrimoniales inconexos, cuyas características y estado de conservación no son determinados. Lo que se proyecta es, en definitiva, una ruta genérica que oferta un mosaico invertebrado de atractivos aislados e independientes sin ningún nexo común agrupados bajo la denominación de tres localizaciones de la sierra norte de Piura (Montero, Ayabaca y Aypate). Dentro de esta lógica, los elementos patrimoniales seleccionados son contemplados únicamente como recursos turísticos mercantilizables sin considerar ni analizar los valores identitarios, históricos, etnológicos y ecológicos, ni la conexión existente entre ellos como un conjunto articulado.

El Corredor Turístico Loja-Ayabaca es un itinerario promovido y financiado por la Agencia de Cooperación Internacional Española para el Desarrollo (AECID) en el marco del Proyecto Binacional de Ordenamiento, Manejo y Desarrollo de la Cuenca Catamayo-Chira que promueve el encuentro y el desarrollo transfronterizo entre Ecuador y Perú tras décadas de conflictos territoriales y bélicos. El diseño del corredor ha correspondido a dos entidades no gubernamentales contratadas por AECID: la Fundación para el Desarrollo Ecológico del Sur (EcoSur) de Loja (Ecuador) y la Asociación Proaves (Perú), cada una de las cuales ha elaborado un diagnóstico en su lado de la frontera. Ambos diagnósticos trazan un recorrido que vincula dos regiones fronterizas mal comunicadas, pero marcadas históricamente por intercambios comerciales, sociales y culturales en un contexto de relativo aislamiento con respecto a los estados 
peruano y ecuatoriano. El corredor turístico se concibe como un instrumento para impulsar y estrechar los lazos entre ambos estados y, paralelamente, como un medio idóneo para frenar la deforestación, la pérdida de biodiversidad de la selva ecuatorial andina y promover el ecoturismo. Este concepto es el que guía un modelo de ruta específica, la cual resalta prioritariamente los valores naturales $\mathrm{y}$, subordinados a estos, otras categorías patrimoniales que completan la oferta. En este sentido, los informes detallan un inventario de los escasos equipamientos turísticos existentes y resaltan los elementos más notables del patrimonio arqueológico y etnológico, que son caracterizados como atracciones turísticas complementarias del recurso más relevante: el patrimonio natural. En este sentido, se subraya la importancia de una serie de espacios de notable valor ecológico, concretamente los bosques primarios nublados y los páramos, los cuales concentran numerosos manantiales y lagunas que aportan agua a las quebradas y valles de los ríos y constituyen el hábitat privilegiado de especies vegetales únicas o excepcionales (líquenes, musgos, helechos, bromelias, orquídeas y plantas trepadoras) y de una fauna muy diversa (más de cien especies de aves, oso de anteojos, tapir de montaña, etc.). Estos espacios son descritos como lugares donde pervive una naturaleza indómita, al tiempo que la cultura local y sus tradiciones son presentadas como manifestaciones atávicas de sociedades campesinas que se mantienen inmutables desde tiempos prehispánicos. El énfasis en la naturaleza virgen y en la cultura intacta genera una imagen idealizada del territorio que es mostrado como un reducto, subrayando atributos considerados muy sugestivos por los turistas globales, pero que no se corresponden con la realidad histórica y cultural de un territorio que ha sido modelado y transformado por el hombre a lo largo de la historia. Desde este enfoque el corredor se concibe como una ruta especifica del patrimonio natural centrada en la visita a enclaves de alto valor ecológico y escenarios donde presuntamente mora atrincherada la autenticidad.

El Proyecto Binacional de Turismo Rural en el Tramo Norte del Camino Inca (Loja-Aypate) que discurre entre la frontera de Perú y Ecuador también se ha proyectado como futuro itinerario cultural transfronterizo. Lo financia la Organización Mundial de Turismo con el apoyo técnico de las Universidades de Piura (Perú) y Loja (Ecuador), la Dirección Regional de Comercio Exterior y Turismo (DIRCETUR), la Casa de la Cultura de Ayabaca y dos organizaciones no gubernamentales: una internacional (Netherlands Development Organisation, SNV) y otra provincial (Escuela Campesina de Educación y Salud, ESCAES). Del mismo modo que las ante- riores propuestas de rutas, las entidades participantes han realizado un inventario de recursos patrimoniales de la zona, con el único objetivo de transformarlos en productos turísticos. En palabras de la responsable de SNV: "Lo fundamental de este proyecto es identificar productos que se inserten al mercado" (Chulucanas Noticias, 13-6-2008). Y en este propósito de mercantilización de la cultura para la seducción de turistas, el legado tangible del pasado funciona como el principal atractivo, especialmente el complejo arqueológico de Aypate, -una ciudad inca bastante desconocida, pero de un gran interés arqueológico y patrimonial. Para ello incluso se recurre a la mistificación histórica ya que, a pesar de la denominación de esta ruta como "Tramo Norte del Camino Inca (Qhapaq Ñan)", el trayecto diseñado no se corresponde totalmente con este recorrido histórico. En toda esta recreación, el patrimonio arqueológico es presentado como un vestigio de un tiempo anterior, mítico, que se emplaza en un territorio vacío y aislado en la virginal selva alta ecuatorial andina. Esta resignificación del territorio y de su patrimonio arqueológico se ajusta a las expectativas de encuentro con la naturaleza, pureza y descubrimiento de lugares ignotos que tanto gusta a amplios sectores de turistas globales. En este concepto, los modos de vida, las costumbres y los rituales de la población autóctona constituyen atractivos subordinados al patrimonio arqueológico y son tratados con los mismos atributos de aislamiento y estatismo que los restos del pasado prehispánico. El recorrido propuesto se ajusta al modelo específico de ruta del patrimonio arqueológico y trata de explotar las ventajas derivadas de la inminente declaración del Camino Inca como Itinerario Cultural de la Humanidad. Sin embargo, el modelo se ajusta más a la propuesta del Consejo de Europa por cuanto los objetivos manifiestos de la propuesta coinciden con los de esta institución pero aplicados a la realidad latinoamericana: fortalecer los lazos transfronterizos y generar un territorio para el consumo de productos turísticos que promueva el desarrollo, aunque dicha propuesta se apoye en débiles fundamentos científicos.

Las tres iniciativas señaladas hasta ahora coinciden en que han sido diseñadas por expertos externos de acuerdo con fórmulas estandarizadas de desarrollo turístico que son aplicables a cualquier realidad. Parten del supuesto Turismo $=$ Desarrollo y de la premisa de que la transformación del recurso patrimonio cultural en producto asegura este desarrollo. Los diagnósticos se han elaborado sin el apoyo de rigurosas investigaciones de campo (etnográficas, arqueológicas, geográficas e históricas) y apenas han contado con las valoraciones de los nativos. No se analizan los modos de vida, tradicio- 
nes y relaciones de la población con su patrimonio ni se plantean sistemas de gestión que involucren activamente a las comunidades campesinas.

Por último, el Programa Integral Qhapaq Ñan es un ejemplo paradigmático de camino histórico, que presenta dos características que lo distinguen de las anteriores propuestas: en primer lugar, la metodología científica e inter-diciplinar empleada en su elaboración y, en segundo, su encuadre como uno de los ejes centrales de la política cultural de Perú que persigue con el proyecto lograr la declaración del Camino Principal Andino (Qhapaq Nan) como Patrimonio Mundial en la categoría de Itinerario Cultural por la UNESCO . Para alcanzar la nominación, el programa integra a los estados de Argentina, Chile, Perú, Ecuador y Bolivia por donde discurría el Qhapaq Ñan, aunque cada uno de ellos lleva a cabo las labores de investigación y conservación del patrimonio en su territorio. Supone un amplio estudio multidisciplinar de todo el camino inca centrado sobre todo en acciones de identificación, conservación y valorización del patrimonio cultural existente para un ulterior desarrollo turístico. Con esta operación, y de acuerdo con los criterios exigidos por ICOMOS, el esfuerzo investigador trata de mostrar al Qhapaq Nan como una red viaria generadora de continuos y fructíferos intercambios culturales entre pueblos que se manifiestan de modo sobresaliente en su patrimonio histórico tangible. Sin embargo, en la propuesta se verifica la rigidez de los criterios propuestos por ICOMOS. En primer lugar, se trata de un camino histórico más que de un itinerario cultural por cuanto los restos arqueológicos constituyen el eje temático del recorrido. Aunque la investigación etnográfica constituye una aportación relevante al conocimiento de aspectos significativos de la realidad cultural de las poblaciones contemporáneas, la ruta se articula en función de los restos arqueológicos y el trazado del Qhapaq Nan. Se produce, por tanto, una jerarquización patrimonial por cuanto el itinerario se justifica antes por el pasado y sus testimonios materiales más relevantes que por el presente y los intercambios culturales contemporáneos generados en la ruta. En segundo lugar, se produce una idealización de los modos de vida de las poblaciones, subrayando aquellas tradiciones vivas cuyas raíces -a veces nebulosas- se puedan vincular al período inca. En este sentido, los elementos del patrimonio etnológico destacados (creencias, mitos, formas de organización social, actividades económicas, manifestaciones festivas, rituales, indumentaria, gastronomía, etc.) lo son en cuanto a pervivencias recreadas de un modo de vida incaico que se presenta como imperturbable. En definitiva, la huella del pasado, su continuidad, es el argumento para la construcción de un territorio fosilizado, estancado, pero muy tractivo para la imaginación turística.

Como se ha indicado, ninguno de estos cuatro proyectos se ha plasmado en una ruta efectiva. En el caso de que alguno de ellos se concrete, las consecuencias sobre la población pueden ser de distinto grado. Con la ruta genérica no se asegura la protección del patrimonio y sí su transformación en mercancía, lo que podría suponer la banalización de sus significados y un distanciamiento de las poblaciones con respecto a su legado cultural. Por su parte, las propuestas de rutas temáticas o específicas (natural y arqueológica) y el camino histórico promocionan un tipo de patrimonio que enfatiza la "autenticidad" y genera nuevos discursos territoriales al margen de las tradiciones de las poblaciones locales, subordinando éstas al patrimonio arqueológico o natural. Asimismo, los cuatro tipos coinciden en ofertar una serie de hitos patrimoniales con grandes vacíos en el entorno de la vía, lo que implica la promoción de las zonas por donde discurre la ruta en detrimento de las adyacentes. La consecuencia probable de este modelo de desarrollo turístico es la fragmentación del territorio, la generación de desequilibrios económicos territoriales y la promoción de una determinada tipología de patrimonio, ignorando o minusvalorando otras categorías.

\section{Consideraciones finales}

En este artículo se ha mostrado que las rutas turísticas constituyen un fenómeno global que se materializa localmente en el marco de estrategias territoriales de dinamización económica y de posicionamiento en el mercado turístico internacional. Sin embargo, en su diversidad, éstas tienden generalmente a la descontextualización del patrimonio, a la desarticulación de los territorios donde se enclavan y a la construcción de imágenes territoriales que no se corresponden plenamente con las realidades sociales y culturales de las sociedades donde se implantan.

Las cuatro rutas analizadas en los Andes Septentrionales de Perú concuerdan con un modelo de desarrollo turístico diseñado externamente con el apoyo de administraciones públicas, organizaciones no gubernamentales y consultoras. En todas ellas se parte de una instrumentalización del patrimonio al servicio del desarrollo turístico o como vía para la nominación e inscripción de itinerarios culturales en la lista del patrimonio mundial. Por ello, en su diseño se promociona un tipo de bienes de acuerdo con los criterios de la UNESCO o con la concepción global de naturaleza y autenticidad que deben acreditar los destinos turísticos para competir con ventaja en el mercado turístico. Esta consideración 
del patrimonio se enfrenta tanto a las visiones autóctonas como a una concepción holística que integra los bienes arqueológicos, históricos, artísticos, ecológicos y etnológicos como un todo dentro de un contexto cultural y territorial determinado. Asimismo, el papel de las poblaciones locales es en las cuatro rutas subsidiario y pasivo. Aunque en los diagnósticos abundan las referencias al desarrollo sostenible y a la participación de la población local, ésta no interviene en la investigación y definición de los recursos culturales, no se plantean modelos de gestión comunitaria del patrimonio y todo apunta a que se espera la atracción de capital externo para la construcción de infraestructuras, la dotación de servicios turísticos y la gestión privada de los recursos patrimoniales.

Son abundantes las investigaciones que, desde la antropología del turismo, constatan la existencia de interesantes experiencias de gestión local de la actividad turística por parte de organizaciones e instituciones que hacen uso del propio patrimonio como un recurso económico y factor de identidad (Ariel, 1995; Bartolomé y Barabas, 1998; Hernández, 2005; Kroshus, 2003; Mitchell y Reid, 2001; Pereiro y de León, 2007; Ruiz, 2008; Tucker, 2001). En ellas se indica que, cuando se produce un control local del patrimonio, esto es, de sus significados y usos, se pueden generar nuevas relaciones entre la población y su patrimonio sin que esto suponga la trivialización de la cultura, así como promover dinámicas de desarrollo endógeno que permitan una reproducción social sostenible. En este sentido, el llamado turismo comunitario (community-based tourism) o etnoturismo, entendido como un modelo turístico liderado por poblaciones que habían sido históricamente objetos antes que sujetos del desarrollo (Ruiz, et al., 2008; Pereiro y De León, 2007), constituye una alternativa a las estrategias turísticas externalizadas, especialmente en territorios periféricos donde prevalece un modelo de organización social basado en comunidades campesinas, tal como ocurre en los andes septentrionales peruanos. Como acertadamente señalan Ruiz, et al, (2008): "es la comunidad en el turismo y no tanto el turismo en la comunidad", es decir, es la comunidad, como instancia organizativa básica, la que puede y debe protagonizar el desarrollo turístico, impidiendo la pérdida de control económico en su territorio, así como la banalización de su identidad y de su patrimonio cultural. De acuerdo con este enfoque, y siendo del todo conscientes de las dificultades y debilidades que el modelo entraña, nuestro planteamiento es que las rutas turísticas se ajusten a la organización comunitaria, contribuyendo a la vertebración territorial, evitando desequilibrios económicos socio-territoriales y promoviendo una visión holística o integral del patrimonio cultural basada en los usos y valores simbólicos autóctonos.

\section{Bibliografía}

Aguilar, Encarnación, Dolores Merino y Mercedes Migens

2003 "Cultura, políticas de desarrollo y turismo rural en el ámbito de la globalización.”. Horizontes Antropológicos, 9 (20): 161-183.

Aguña, María Isabel

2002 "La larga trayectoria del desarrollo turístico en la montaña palentina". Cuadernos de Turismo, 10: 123-136.

Ariel de Vidas, Anath

1995 "Textiles, Memory and the Souvenir Industry in the Andes". En Lanfant, Marie-Françoise, John B. Allcock y Edward M. Bruner (Eds.), International Tourism. Identity and Change (pp. 67-83). London: Sage.

Bartolomé, Miguel A. y Alicia Barabas

1998 "Recursos culturales y autonomía étnica. La democracia participativa de los kuna de Panamá". Alteridades, 8: 159-174.

Briedenhann, Jenny y Eugenia Wikens

2003 "Tourism routes as a tool for the economic development of rural areas. Vibrant hope or impossible dream?" Tourism Management, 57: 1-9.

Campesino, Antonio José

2006 "Controversia patrimonial". PH. Boletín del Instituto Andaluz del Patrimonio Histórico, 60: 1.

Campesino, Antonio José

2006 "Ciudades abaluartadas de la raya ibérica: de frontera a paisaje cultural". PH. Boletín del Instituto Andaluz del Patrimonio Histórico, 60: 74-83.

Campos, María Lourdes

2006 "Ruta de Don Quijote. Un personaje literario... un producto turístico". PH. Boletín del Instituto Andaluz del Patrimonio Histórico, 60: 126-129.

Capel, Horacio

2005 "Las rutas culturales como patrimonio de la $\mathrm{Hu}$ manidad. El caso de las fortificaciones americanas del Pacífico". Biblio 3W. Revista Bibliográfica de Geografía y Ciencias Sociales, X (562): 1-25.

Denstadli, Jon M. y Jens S. Jacobsen

2010 "The long and winding roads: Perceived quality of scenic tourism routes". Tourism Management (in press).

Fernández, Guillermina y Aldo Guzmán

2005 "Patrimonio industrial y rutas turísticas culturales". Cuadernos de Turismo, 15: 97-112. 
Filardo, Verónica

2006 "Globalización y turismo: impactos en los territorios". Pampa, Revista Interuniversitaria de Estudios Territoriales, 2: 185-217.

García de Miguel, J. M.

2002 "Itinerarios culturales relacionados con el patrimonio histórico minero". En AA.VV. El patrimonio intangible y otros aspectos relativos a los itinerarios culturales (pp. 145-157). Pamplona: Gobierno de Navarra.

Giddens, Anthony

1993 Consecuencias de la modernidad. Madrid: Alianza Editorial.

Herbert, David

2001 "Literary places, tourism and the heritage experience". Annals of Tourism Research, 28 (2): 312-333.

Hernández, Javier

2005 "Cine, Turismo y Cultura”. En Cao, M. V., J. Hernández, R. Plasencia y M. Salinas (Coord.) El cine visto por los antropólogos (pp. 9-29). Lima: Universidad Nacional de San Marcos.

2005 "Activando la memoria, mirando al futuro. Patrimonialización de un oficio perdido y dinamización turística”. En Pascual, José y David Florido ¿Protegiendo los recursos? Áreas protegidas, poblaciones locales y sostenibilidad (pp. 173-186). Sevilla: ASANA. FAAEE.

Inglis, David y Mary Holmes

2003 "Highland and other haunts. Ghosts in Scottish tourism". Annals of Tourism Research, 30 (1): 50-63. Instituto Nacional de Cultura

2006 Pueblos y culturas en las rutas del Qhapaq Ñan. Informes de Investigación etnográfica. (2 volúmenes). Proyecto Qhapaq Ñan: Lima (Perú).

Instituto Nacional de Cultura

2008 Reconocimiento y registro del entorno territorial del Qhapaq Ñan. Proyecto Qhapaq Ñan: Lima (Perú).

Instituto Nacional de Cultura

2009 Apu Pariacaca y el Alto Cañete. Estudio de Paisaje Cultural. Programa Qhapaq Ñan: Lima (Perú).

Kroshus, Laurie

2003 "La comercialización cultural. El turismo y la identidad maya". Annals of Tourism Research en Español, 5 (1): 86-103.

Lagunas, David

2006 "El espacio del turismo". Alteridades, 16 (31): 119129.

López-Guzmán, Tomás y Sandra Sánchez

2008 "La creación de productos turísticos utilizando rutas enológicas". Pasos, Revista de Turismo y Patrimonio Cultural, 6 (2): 159-171.
López Roig, Jordi

2008 "El turismo ornitológico en el marco del postfordismo, una aproximación teórico-conceptual”. Cuadernos de Turismo, 21: 85-111.

Mitchell, Ross y Donald Reid

2001 "Integración comunitaria. Turismo insular en Perú". Annals of Tourism Research en Español, 3 (1): 144-172.

Nogués, Antonio Miguel

2006 "Ruralismo y tecnotropismo: turismo y desarrollo en la Bonaigua". Pasos, Revista de Turismo y Patrimonio Cultural, 4 (1): 53-68.

Otamendi, Alejandro

2008 "El turismo místico-esotérico". RBTur Revista Brasileira de Pesquisa em Turismo, 2 (2): 20-40.

Palti, Elías

2001 "Introducción". En Koselleck, Reinhart Los estratos del tiempo: estudios sobre la historia (pp. 9-42). Barcelona: Paidós.

Pereiro, Xerardo y Cebaldo de León Smith

2007 Los impactos del turismo en Kuna Yala (Panamá). Turismo y cultura entre los Kuna de Panamá. Madrid: Ramón Areces.

Proyecto Andalucía Barroca, 2007

2006 "Itinerarios temáticos de la Andalucía Barroca". $\mathrm{PH}$. Boletín del Instituto Andaluz del Patrimonio Histórico, 60: 34-47.

Rengifo, Juan Ignacio

2006 "Rutas culturales y turismo en el contexto español”. PH. Boletín del Instituto Andaluz del Patrimonio Histórico, 60: 114-125.

Ruiz, Esteban, M. Hernández, A. Coca, P. Cantero y A. Del Campo

2008 "Turismo comunitario en Ecuador. Comprendiendo el community-based tourism desde la comunidad". Pasos. Revista de Turismo y Patrimonio Cultural, 6 (3): 399-418.

Ruiz Ballesteros, Esteban

2008 Agua Blanca. Comunidad y turismo en el Pacífico ecuatorial. Quito: Abya-Yala.

Suárez-Inclán Ducassi, María Rosa

2004 "Los itinerarios culturales". The CIIC Scientific Magazine. http://www.esicomos.org/nueva_carpeta/ TCSM/TCSM indice.htm

Tondre, Francoise

2007 "El Patrimonio Cultural y los Itinerarios Culturales del Consejo de Europa: nuevas orientaciones, caminos hacia la diversidad, puentes entre las comunidades". En AA.VV Caminos de Sefarad. Memoria 2007 (pp. 28-34). Jaén: Red de juderías de España.

Tucker, Huzel

2001 "Turistas y trogloditas. Negociando la sostenibili- 
dad". Annals of Toursim Research en Español, 3 (2): 259-286.

Urry, John

2008 "La globalización de la mirada del turista. Sobre turistas y turismo". Barcelona Metrópolis. Revista de información y pensamientos urbanos. http://www. barcelonametropolis.cat/es/page.asp

Zamora, Elías y Rafael Merinero

2003 "Patrimonio Cultural, turismo y desarrollo endógeno. El caso de la "ruta del Tempranillo". En Antonio. M. Nogués (Coord.), Cultura y turismo (pp. 83-109). Sevilla: Signatura Ediciones.

Fuentes documentales

Consejo de Europa

1998 Resolución (98) 4 sobre los Itinerarios Culturales. Adoptada por el Comité de Ministros el 17 de marzo de 1998 en la $623^{\text {a }}$ reunión de los delegados de ministros.

\section{ECOSUR}

2003 Diagnóstico del corredor turístico Loja-Ayabaca (sector Loja: Columbo-Yacuri). Ecosur:Loja (Ecuador).

\section{ICOMOS}

2008 Carta de Itinerarios Culturales. Comité Científico Internacional de Itinerarios Culturales (CIIC). Asamblea General del ICOMOS: Québec (Canadá)

TM Consultores Asociados SAC

2008 Desarrollo Turístico de la Ruta Montero-AyabacaAypate. Diagnóstico Situacional. Lima: Perú.

\section{UNESCO}

2005 Directrices Prácticas para la Aplicación de la Convención del Patrimonio Mundial. Comité Intergubernamental de Protección del Patrimonio Mundial cultural y natural. Centro del Patrimonio Mundial: París. http://whc.unesco.org

PROAVES PERÚ

2003 Diagnóstico del corredor turístico Loja-Ayabaca (Sector Espíndola-Ayabaca). Proaves: Sullana, (Perú).

\section{NOTAS}

1. La definición de Itinerario Cultural elaborada por el Comité Científico Internacional de Itinerarios Culturales (CIIC) y ratificada por la asamblea general de ICOMOS en 2008 es la siguiente: Toda vía de comunicación terrestre, acuática o de otro tipo, físicamente determinada y caracterizada por poseer su propia y específica dinámica y funcionalidad histórica al servicio de un fin concreto y determinado (2008:2). Esta vía debe, según ICOMOS, ser un espacio de intercambios multidimensionales, continuos y recíprocos capaz de generar una gran riqueza patrimonial y fecundas relaciones históricas entre distintos pueblos (ICOMOS, 2008:2).

2. La nueva categoría patrimonial de UNESCO es, sin duda, un avance por cuanto desarrolla un enfoque que supera al de monumento aislado, valorando conjuntos patrimoniales como sistemas dentro de entornos culturales y ecológicos concretos.

3.En 2001 el gobierno del Perú declaró de interés nacional la investigación, registro, conservación y puesta en valor del Qhapaq Nan (Decreto Supremo N ${ }^{\circ}$ 0312001-ED). Posteriormente, a finales de 2004, este decreto fue reforzado con la promulgación de la Ley $\mathrm{N}^{\circ}$ 28260 (http://inc.perucultural.org.pe). $\begin{array}{ll}\text { Recibido: } & 28 / 01 / 10 \\ \text { Reenviado: } & 22 / 01 / 11 \\ \text { Aceptado: } & 15 / 02 / 11\end{array}$

Sometido a evaluación por pares anónimos 